\title{
¿Etnias, desarrollo sostenible?
}

\section{Ethnic, sustainable development?}

\section{Gladis Eufemia Arango Carvajal ${ }^{*}$}

\section{Resumen}

La relación que establecen las etnias Embera Dóbida y Embera Chami con la naturaleza, es de simbiosis en que el "mundo material" alterna con el "mundo espiritual" donde cobran vida las plantas, se conservan los ecosistemas asociados con la selva tropical húmeda, pero no garantizan la seguridad alimentaria, lo que implica generar conocimiento en cómo hacer más productivo el suelo y su aplicabilidad en los territorios de estas comunidades para lograr un desarrollo sostenible.

Palabras clave: Conservación, Desarrollo sostenible, Etnia Embera Chamí, Etnia Embera Dóbida, Inseguridad alimentaria.

\section{Abstract}

The relationship established by the Embera Dóbida and Embera Chami ethnic groups, with the nature of symbiosis, in which the "material world" alternates with the "spiritual world", where the plants come alive, the ecosystems associated with the humid tropic forest are conserved but, they do not guarantee food security, which means generating knowledge on how to make the soil more productive and its applicability in the territories of these communities, to achieve their sustainable development.
* Antropóloga, Universidad de Antioquia. Contratista del Instituto de Investigaciones Ambientales del Pacífico (IIAP), Quibdó, Chocó. e-mail: gladisarangoc@hotmail.com

Keywords: Conservation, Embera Chami ethnic, Embera Dóbida ethnic, Food insecurity, Sustainable development.

Las etnias Embera Chamí y la etnia Embera Dóbida $^{1}$, en la cosmovisión del medio natural, conciben la pervivencia de un "mundo espiritual"

Se refiere a las comunidades indígenas El Veinte de la etnia Embera Chamí y la comunidad El Veintiuno de la etnia Embera Dóvida, ubicadas en la vía Quibdó-Medellín, jurisdicción del municipio de Quibdó, departamento del Chocó, Colombia. alterno con el material que se vislumbra en las plantas, en los sitios sagrados, en el árbol sagrado, en las enfermedades, entre otras manifestaciones; "espíritus" del mundo sobrenatural que los rigen. Los espíritus en relación con los árboles y plantas, es un atributo que se le confieren para significar y considerarlas como seres vivos, que sienten, que lloran, curan, con las que interactúan en 


\section{Bioetnia Volumen 14, 2017}

una relación de respeto y de dependencia; hechos que se manifiestan como lo expone el señor Tunay de la etnia Embera Dóbida:

Los espíritus están en todo el bosque, para que levante el mismo. Cuando usted lo va a cortar espera cinco minutos, y sale un agua, es la sangre y, el árbol está llorando porque lo van a cortar, porque ya uno lo va a matar. Por eso cuando va a tumbar, se hace rápido porque uno siente dolor porque lo va a matar. Nosotros no conocemos el monte, no sabemos que habla ese árbol. Toda planta tiene espíritu, en la limpieza ${ }^{2}$, uno da cuenta que llora, porque da un machetazo, por eso los arranca mucho y rápido, pa que no duela (E. Tunay, comunicación personal, 25 de agosto de 2017).

El árbol considerado sagrado es el Lano Blan$\mathrm{Co}^{3}$, que otorga el espíritu a un indígena para ser Jaibaná y se realiza mediante una ceremonia, el señor Tunay, dice al respecto:

Se compra cigarrillos y aguardiente, se consiguen cuatro hojas blancas y a las seis de la tarde, debajo del árbol se limpia y tienden las hojas, por encima de estas, se ponen 12 vasos y se echa la media de aguardiente en los vasos, va tomando para no dormirse; a las doce de la noche por encima del árbol se va a sentir una música, es que el árbol va a entregar el espíritu, si no suena la música no entrega el espíritu, tiene mal corazón. Nosotros los Embera respetamos esos árboles, en las ramas aparecen unas ranas de ojos claros y más de mil ranas, como sapos de grandes lijas de muchos colores, negro con azul, negro con rojo, negro con amarillo. Si el árbol se va a mirar a las doce del día, se ve como una persona. El sábado en la tarde

\footnotetext{
Se refiere al deshierbe que se realiza en los cultivos. Según Córdoba (2008) el lano blanco es de la familia Annonaceae de la especie Xylopiasp.
}

y el domingo se escucha tocar una música (E. Tunay, comunicación personal, 25 de agosto de 2017).

Los espíritus en relación con las plantas medicinales, lo relata el señor Tunay que es yerbatero:

Yo ya sé dónde están las plantas medicinales, llego allá y tiro mi palabra a la mata, yo digo: voy cogiendo a usted pa que me haga un favor, para que me cure esa enfermedad. Sí es de brujo, ayúdeme a curar o sacar esta enfermedad, no quiero que quede pegado en el cuerpo, quiero que me ayude para que otro día piense, que a nosotros le salvo la vida.

Establece una relación de igualdad entre el hombre y la planta donde esta cobra mucho significado al darle el don de la curación. Por su parte, el señor Velásquez de la etnia Embera Chamí, dice:

Al encontrar la planta que voy a utilizar, le hablo antes de arrancarla, le echo bendiciones y le digo que es para curar al enfermo y que lo aliente, pero alentado, como la planta se paró, que pare al enfermo. Después le pido permiso para arrancarla y llevármela. Luego entierro el tallo, si solo necesito la raíz para la cura; no puedo dejarla tirada, la siembro para encontrarla otra vez.

En algunas curas que solo necesita las hojas o las flores también realiza el mismo rito. Son los espíritus, en medio del ritual que realiza el Jaibaná al frente del enfermo, quienes identifican las enfermedades y le dice las plantas para la curación; el Jaibaná es el mediador como dice el señor Velásquez:

Los espíritus dejan ver la enfermedad y dicen las plantas(comunicación personal 10 de agosto de 2017). 
Entre las concepciones que se tiene del territorio, una indígena de la comunidad el Veintiuno ${ }^{4}$ manifiesta:

Del bosque se aprende muchas cosas, sobre las plantas curativas, del sitio sagrado, donde hay $\mathrm{Jai}^{5}$ que se debe respetar, del árbol sagrado para aprender a ser Jaibaná. Todo es importante; los espíritus que se pueden encontrar en el monte, no se pueden ver a simple vista, hay espíritus buenos y hay espíritus malos. Es importante para la comunidad porque el saber y el conocimiento se coge con el bosque, porque la relación esta con nuestra tierra y cada día más, van a tener más conocimiento, es la sabiduría".

Según el señor Tunay:

El territorio, es gran alimento porque con la tierra se maneja la familia, animales de monte, si no tiene tierra no puede conseguir nada de alimento, de animales de monte. Es importante porque hay que cuidar la madre tierra, es importante la cultura que hay que cuidar (E. Tunay, comunicación personal, 25 de agosto de 2017).

Según el señor Velásquez, habitante de la comunidad El Veinte dice:

Para nosotros el territorio es en general y abarca mucho, es como si estuviéramos hablando de mi madre tierra, todo lo da, la casa, los alimentos, da todo gratis, como si nosotros fuéramos los hijos, porque si yo siembro una semilla de piña, o de plátano, esta sale de sus entrañas; aporta las semillas, las vitaminas (C. Velásquez, comunicación personal, 5 de septiembre de 2017).

4 Exponiendo, un mapa social en un taller realizado el día 19 de agosto 2017 en la comunidad indígena El Veintiuno.

5 Jai es otra denominación para espíritu.
En estas comunidades con cada nacimiento, se recrea la conexión del hombre y la naturaleza. La señora Arce de la comunidad indígena El Veinte, expresa ${ }^{6}$

Cuando se entierra el ombligo es la forma de ligarse a la madre tierra, después de los cuatro días, que se le cae el pedazo de ombligo, se entierra en un sitio, donde también se siembra un árbol y se entierra la placenta (M. Arce, comunicación personal, 14 de octubre de 2017).

Además, se realiza la ombligada y es, untarle en el ombligo alguna sustancia de origen animal o vegetal, que le da un atributo al niño o la niña hasta la edad adulta y está directamente relacionada con la habilidad del animal o la propiedad de la planta. Arce dice:

Untarle al ombligo el sumo de la planta de salvia, es para que tenga la sangre amarga, para que ningún espíritu malo le haga daño. Si se quiere que sea cazador, se ombliga con el oso hormiguero, o el mico, o el animal que le parezca más hábil. Si se quiere pescador se ombliga con la anguila o el veringo (M. Arce, comunicación personal, 14 de octubre de 2017).

El señor Tunay de la comunidad el Veintiuno, revela:

Cuando se cae el ombligo se lleva y entierra en la finca, se siembra un árbol, el que quiera y, el niño será el dueño. La planta sembrada da cuenta cómo va a quedar el

6 Manifiesta que, en una reunión de las mujeres en la zona, se planteó la preocupación porque en los últimos cuatro años algunas indígenas les han realizado cesárea, y la placenta termina en los desechos del hospital y que debería plantearse por parte de las indígenas, solicitar que se le entregue la placenta para que se entierre en el resguardo, porque es lo que los liga a la tierra y arraigo al territorio. 


\section{Bioetnia Volumen 14, 2017}

muchacho, sí la planta esta bonita, él va a estar alentado. Para ombligar, si se quiere que aprenda a sembrar, a un recién nacido se ombliga con el guatín, es el animal que dispersa las semillas, porque se lleva en la boca los frutos que se va a comer. Si se quiere que tenga fuerza se ombliga con el perico o el perezoso. Se raspa el hueso o la uña del animal y es lo que se hecha en el ombligo (E. Tunay, comunicación personal, 21 de octubre de 2017).

Solo escuchar estos relatos de la relación cotidiana con las plantas y la "madre tierra", se puede comprender y cobra sentido, para la mirada del otro (otra cultura), la concepción y percepción diferente del medio natural que tienen las comunidades indígenas. La cosmovisión y cosmogonía de lo ambiental, lo cultural y económico, están íntimamente ligados, es una simbiosis; en un contexto de selva tropical húmeda biodiversa. Es lo que ofrece la diversidad étnica, en el país.

Estas culturas étnicas han forjado un "modelo de desarrollo", "alterno", en que prima la conservación de los ecosistemas, en oposición con el modelo de desarrollo capitalista, que instaura la economía de mercado (oferta y demanda), de bienes y servicios, en que los medios de producción, se concentran en unos pocos (propiedad privada); prima el capital y en los procesos productivos la obtención y acumulación de ganancias o excedentes, a costa en algunos de estos procesos de arrasar con los ecosistemas. Han subsistido simultáneamente ambos modelos $\mathrm{y}$, evidencian que el "desarrollo" no es unilineal por la que deben pasar necesariamente todas las sociedades.

El concepto de desarrollo sostenible fue descrito en 1987 en el informe de la Comisión de Bruntland como un "desarrollo que satisface las necesidades de la generación presente, sin comprometer la capacidad de las generaciones futuras de satisfacer sus propias necesidades" (Wilches 1997). Como una voz de alerta para frenar o re- considerar lo que se estaba presentando, con el agotamiento de los recursos naturales y advertir que no eran tan renovables como se pregona décadas atrás, y que la presión antrópica sobre el medio es tan alta que excede la capacidad de reproducción de los ecosistemas.

El grado de conservación de los ecosistemas donde viven estas comunidades indígenas en comparación con la destrucción o sobreexplotación del ambiente de otros grupos humanos, "culturas depredadoras", se podría plantear que es un desarrollo sostenible. Pero sí se analiza a las comunidades indígenas que se conciben solo en un territorio, que les aporta las condiciones para la supervivencia física y cultural, como grupos humanos cohesionados por su identidad cultural y "sociedades cerradas". Con inseguridad alimentaria debido a la crisis del sistema de producción tradicional (suelos poco fértiles), aunado con agotamiento de los animales que se cazan, escases de peces y se agudizó con el conflicto interno armado por el confinamiento, que generó abandono de cultivos más alejados del asentamiento y la libre movilidad para realizar las diferentes actividades en el resguardo; en este sentido el concepto de desarrollo sostenible que define un desarrollo quesatisface las necesidades de la generación presente, en estas comunidades no logra cumplir con este parámetro.

Uno de los factores que inciden en la improductividad, son las condiciones del suelo en un ecosistema de selva tropical húmeda, por lo que se requiere investigar y aplicar un sistema apropiado para mejorar las condiciones del mismo, para asegurar el desarrollo sostenible y seguir con los sistemas tradicionales de producción en el contexto de la silvicultura. Es darle la importancia al recurso suelo, como factor determinante en la producción y abastecimiento de alimentos para garantizar la seguridad alimentaria, sostenible en el tiempo.

La concepción de desarrollo, de vivir en armonía con la naturaleza, de estas comunidades indí- 
genas propicia la conservación de los ecosistemas y la biodiversidad asociada con la selva tropical húmeda, con un potencial genético y servicios ecosistémicos aun por explorar que contribuirían a mejorar las condiciones socioeconómicas además de contribuir con la mitigación del cambio climático, como un aporte de estas etnias ubicadas en el Chocó Biogeográfico.

\section{Literatura citada}

Córdoba L. 2008. Inventario y uso de especies maderables en el corregimiento de la Troje, Chocó, Colombia. Quibdó: Universidad Tecnológica del Chocó(on-line). Disponible en: http://docplayer.es/68148247-Inventario-y-uso-de-especies-maderables-en-el-corregimiento-de-la-troje-choco-colombia.html

Wilches G. 1997. Y qué es eso, desarrollo sostenible? Bogotá: DNP; Florencia: Consejo Regional de Planificación; 99 pp. 